\title{
8
}
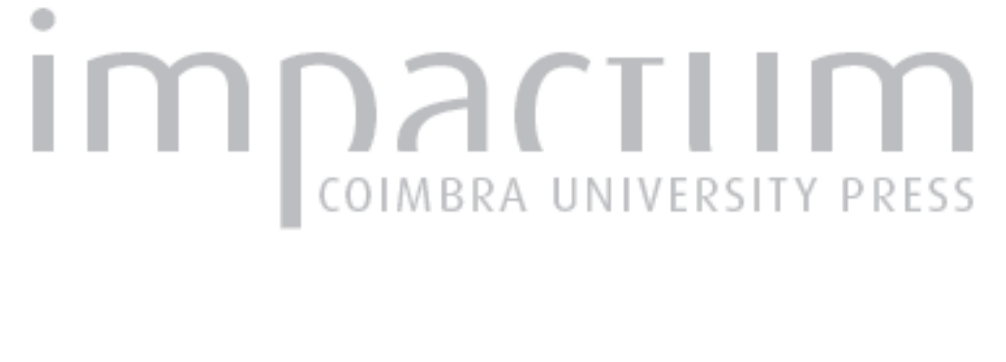

\section{Plutarco, vida de Rómulo: algumas reflexões sobre velhos problemas}

\author{
Autor(es): Leão, Delfim F.
}

Publicado por: International Plutarch Society

URL persistente:

URI:http://hdl.handle.net/10316.2/37626

DOI:

DOI:http://dx.doi.org/10.14195/0258-655X_4_5

Accessed : $\quad$ 26-Apr-2023 15:46:56

A navegação consulta e descarregamento dos títulos inseridos nas Bibliotecas Digitais UC Digitalis, UC Pombalina e UC Impactum, pressupõem a aceitação plena e sem reservas dos Termos e Condições de Uso destas Bibliotecas Digitais, disponíveis em https://digitalis.uc.pt/pt-pt/termos.

Conforme exposto nos referidos Termos e Condições de Uso, o descarregamento de títulos de acesso restrito requer uma licença válida de autorização devendo o utilizador aceder ao(s) documento(s) a partir de um endereço de IP da instituição detentora da supramencionada licença.

Ao utilizador é apenas permitido o descarregamento para uso pessoal, pelo que o emprego do(s) título(s) descarregado(s) para outro fim, designadamente comercial, carece de autorização do respetivo autor ou editor da obra.

Na medida em que todas as obras da UC Digitalis se encontram protegidas pelo Código do Direito de Autor e Direitos Conexos e demais legislação aplicável, toda a cópia, parcial ou total, deste documento, nos casos em que é legalmente admitida, deverá conter ou fazer-se acompanhar por este aviso.

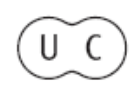


PLOUTARCHOS, n.S. Scholarly Journal of 18

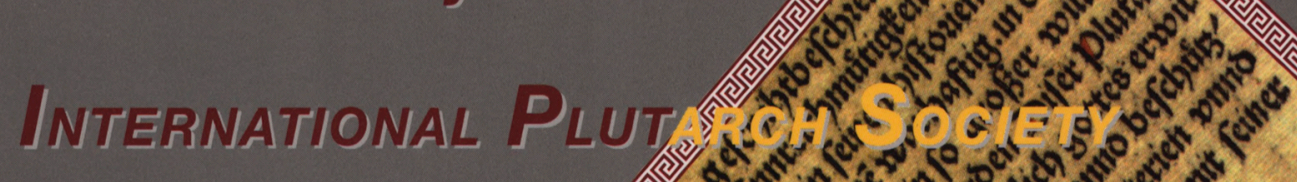

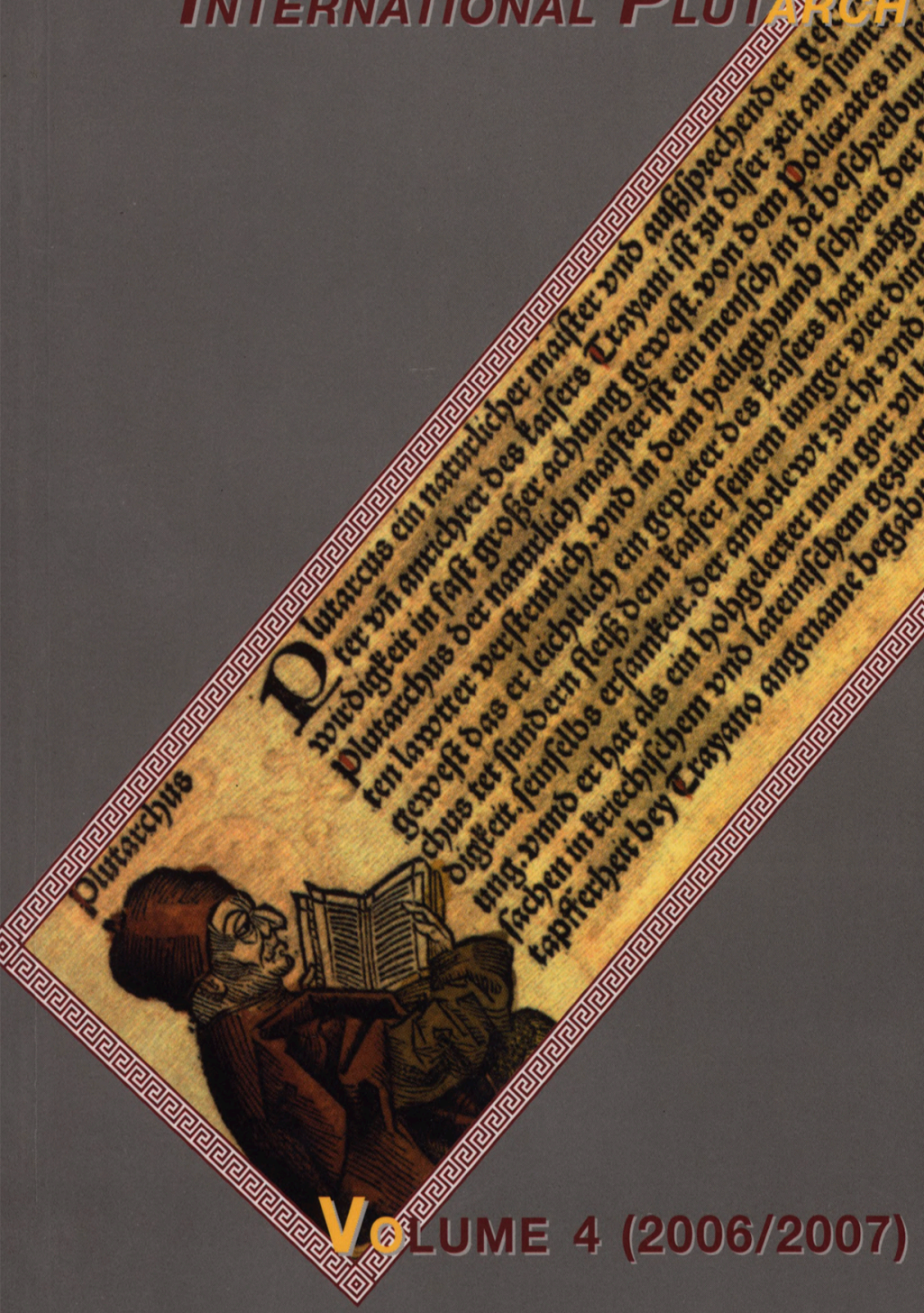

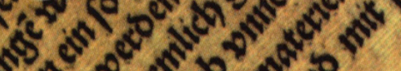

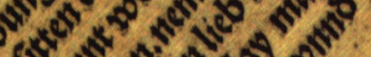

$120^{2} 0^{2} x^{2} x^{2}$

$4 \sin ^{\circ} \cos ^{\circ}$

singes

$0^{2}+0^{2} \mathrm{~s}^{\circ}$

$a^{5} x^{2}$

$s^{5}+\omega^{\circ}$

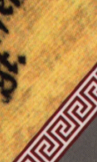

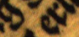

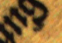




\title{
Plutarco, Vida de Rómulo: Algumas reflexões sobre velhos problemas \\ por \\ Delfim F. Leão \\ Universidade de Coimbra
}

\begin{abstract}
The author discusses the way how, in the portrait of the mythical founder of Rome, we may find some of the traits of an 'ethnic genoma' that shall characterize the Romans as heirs of a particular cultural patrimony, a kind of Romanitas, created by the way Romans saw their mythical ancestors and liked to be seen through the eyes of the non Romans
\end{abstract}

O proémio da biografia de Teseu (Thes. 1.1-3) é um passo justamente célebre, na medida em que, nestes parágrafos iniciais, Plutarco mostra estar bem consciente dos problemas acrescidos que implicava discutir figuras cuja existência se afastava da factualidade histórica, para aproximar-se de matérias geralmente mais aptas a serem tratadas por poetas e mitógrafos. O autor começa, aliás, por expor essa dificuldade através de um significativo paralelismo com a geografia, recordando que a operação que se prepara para iniciar equivale, de alguma forma, às notas explicativas que os cartógrafos escrevem à margem dos mapas, quando se referem a zonas cujo conhecimento não dominam. É desse terreno movediço da archaiologia que Plutarco reconhece estar agora a aproximar-se, depois de publicar as Vitae de Licurgo e Numa. No entanto, a fim de minimizar os riscos de uma empresa que poderia afigurar-se temerária aos olhos de um leitor mais crítico, o biógrafo compromete-se ao esforço metodológico de submeter o passado mítico (to mythodes) a um processo de racionalização (logos), que permita revestir os relatos fabulosos de uma aceitável aparência histórica ${ }^{1}$.

A abertura da Vita serve, igualmente, de justificação para a escolha do par

1 Sobre as marcas do racionalismo de Plutarco nas biografias de Teseu e de Rómulo, vide sistematização de AMPOLO (1993) xi-xvii. Mais adiante, iremos retomar esta questão.

PLOUTARCHOS, n.s., 4 (2006/2007) 57-66.

ISSN 0258-655X 
Teseu-Rómulo, seleccionado para ilustrar a origem das duas cidades mais marcantes da antiguidade clássica: Atenas e Roma. De resto, elas simbolizam metaforicamente o regime democrático e o império romano (tal como o biógrafo o conhecia na viragem do séc. I para o II da nossa Era) e cujos heróis fundadores representam ainda, como veremos, enquanto expressão de uma espécie de 'genoma étnico', as características civilizacionais que hão-de marcar Atenienses $\mathrm{e}$ Romanos. A selecção das figuras a retratar não era indiferente, pois embora Teseu já tivesse, ao menos desde o séc. V a.C., contornos 'históricos' e políticos bastante definidos e fosse a incarnação por excelência do espírito ático, a verdade é que alguns autores, antes de Plutarco, preferiam ver em Licurgo (o lendário criador da constituição espartana) uma personalidade naturalmente mais talhada para alinhar com Rómulo enquanto símbolos de nações com grandes capacidades bélicas e com uma constituição bastante estável ${ }^{2}$. Para mais, Teseu não fora propriamente o fundador de Atenas, mas antes o responsável pelo sinecismo de várias povoações já existentes, se bem que tenha sido essa agregação o factor que potenciaria a afirmação da Ática enquanto pólis. Quanto a Rómulo, os antigos viam nele efectivamente o fundador de Roma, numa data que situavam em meados do séc. VIII a.C., se bem que também eles se apercebessem de algumas das dificuldades cro- nológicas criadas por esta forma de organizar o passado, em especial no que se referia à articulação com os relatos da viagem de Eneias até ao Lácio. Uma vez que, tradicionalmente, a guerra de Tróia era colocada à volta do séc. XII a.C., Eneias teria fundado Lavínio pouco depois e, por conseguinte, os gémeos não poderiam estar ligados a esse herói por um laço de parentesco próximo, na medida em que, entre as duas figuras, mediavam cerca de quatrocentos anos. Ora esse lapso cronológico vai ser preenchido pela dinastia dos reis albanos, iniciada por Ascânio, filho de Eneias, ao fundar Alba Longa. Este pormenor mostra que a saga de Tróia não pertence ao núcleo originário das lendas fundacionais e tem, por conseguinte, uma génese diferente, ligada ao mundo heroico da epopeia. Em todo o caso, o papel de Eneias acaba por ser secundário para os nossos objectivos, na medida em que a escolha de Plutarco recaiu sobre a vertente da lenda mais genuinamente romana e é essa, portanto, que agora nos interessa.

$\mathrm{Na}$ altura em que o biógrafo compunha as Vitae, os dados relativos à fundação de Roma estavam já perfeitamente cristalizados e, porque Plutarco não se desvia muito das grandes linhas da vulgata fixada pelo tempo, valerá a pena recordar os pontos essenciais da tradição, bem como os aspectos sujeitos a maior controvérsia, uma vez que os vamos reencontrar, regra geral, na Vida 
de Rómulo, embora filtrados pela sensibilidade ética e estética do autor e ainda pela preocupação de não hostilizar os Romanos, cuidado aliás facilmente compreensível na óptica de um grego que reconhecia e não deixava de apreciar o poder e capacidade de organização dos dominadores latinos.

Assim, a maioria das fontes antigas aceitava que Rómulo e Remo haviam nascido de Reia Sílvia, filha do rei Numitor, o legítimo herdeiro do trono albano, o qual fora deposto pelo irmão Amúlio. Como forma de prevenir a eventual reivindicação do sólio por algum descendente de Numitor, Amúlio obrigou a sobrinha a fazer-se Vestal. Dado que as servidoras de Vesta tinham de permanecer virgens, o nascimento dos gémeos encontrava-se, de certa forma, envolto em polémica e infracção, o que teria facilitado a decisão de Amúlio de mandar lançar as crianças ao Tibre. Da piedade ou receio da pessoa encarregada de cumprir a sentença resultou que os dois irmãos foram colocados numa cesta que, ao ser arrastada rio abaixo pela correnteza, acabaria depositada no banco de areia de uma das margens. Uma vez aí, os gémeos começaram por ser amamentados por uma loba, até que uns pastores os recolheram e criaram. Rómulo e Remo cresceram nesse meio, ignaros da verdadeira identidade, embora as suas naturais qualidades de liderança os projectassem como chefes dos companheiros, que se envolviam em frequentes escaramuças e bravatas com outros pegureiros, piratas e ladrões que actuassem na região. Ao tomarem conhecimen- to da real ascendência, os gémeos atacaram Alba Longa e repuseram no trono o avô, Numitor, embora optassem por não permanecer na cidade, cujo governo lhes caberia mais tarde por direito. Em vez disso, decidiram fundar uma colónia de Alba Longa, no local onde haviam sido salvos. A nova urbe acabaria por chamar-se Roma, designação que derivaria de Rómulo, depois de ele ter assassinado o irmão numa querela fútil, por alturas da delimitação das muralhas da cidade. Roma conheceu um crescimento rápido, devido sobretudo à grande capacidade de integração e acolhimento de outras pessoas, mesmo de elementos marginais e potencialmente perigosos, se bem que o futuro a médio prazo se visse comprometido pela falta de mulheres; daí o episódio do rapto das mulheres sabinas e posterior integração dos Sabinos, traduzida na partilha do governo entre Rómulo e Tito Tácio. Roma continuou a aumentar em poder e importância demográfica, numa expansão rápida, justificada essencialmente por dois factores: por um lado, a poderosa força bélica, que ora atraía e forçava a celebração de alianças com os vizinhos ora permitia infligir pesadas derrotas aos inimigos; por outro, a enorme capacidade para absorver elementos externos, fossem imigrantes, confederados ou mesmo as partes vencidas em conflito.

Apesar da concordância genérica em relação a estes elementos, as fontes não deixam, ainda assim, de comportar inúmeras disputas e variantes no respeitante a questões de pormenor. Valerá a pena evocar, igualmente, os principais 
dados objecto de discussão. A controvérsia começava logo pela paternidade dos gémeos; a maioria das fontes apontava o deus Marte, solução que reunia evidentes vantagens: enobrecia as origens de Roma, ao misturar elementos humanos e divinos, além de que ter Marte como pai era um cenário muito conveniente a um povo que se afirmara pela capacidade bélica ou 'marcial'; para mais, esta solução ilibava Reia Sílvia da acusação de não ter observado voluntariamente a castidade. Ainda assim, havia outros candidatos à paternidade, como um espectro saído da terra (hipótese que salvaguardava a ideia de intervenção divina) ou simplesmente o próprio Amúlio, que se disfarçara de Marte para violentar a sobrinha. Objecto de especulação era ainda a identificação da loba que amamentara os gémeos; de facto, em Latim, o termo lupa é ambíguo, pois tanto pode significar 'loba' como 'prostituta', de modo que a racionalização do mito implicava tão-somente a diferença entre uma leitura enobrecedora ou, muito pelo contrário, aviltante. Idêntica discussão motivava o contexto em que ocorrera a morte de Remo, oscilando os juízos entre a recriminação aberta de Rómulo (que vinha enganando o irmão já desde a consulta do voo das aves, a propósito da decisão sobre o nome e localização da futura cidade) ou as tentativas de desculpabilização, assumindo que havia sido antes um companheiro de armas (Célere) a desferir o golpe mortal. Rómulo enfrentava a mesma ambivalência interpretativa relativamente às circunstâncias que levaram ao assassinato do sabino Tito Tácio ou à sua própria morte; no primeiro caso, era, no mínimo, acusado de alguma incúria na maneira como procurara fazer justiça à morte do colega de governo, chegando inclusive a enfrentar a suspeita de ele mesmo ter organizado o golpe, a fim de ficar sozinho à frente de Roma. Quanto ao desaparecimento do seu corpo, no termo de uma progressiva cedência aos vícios da tirania, especulava-se se teria ocorrido por conjura do senado se por intervenção divina: por outras palavras, se o homicídio fora politicamente motivado ou se se tratara antes da apoteose do herói fundador.

$\mathrm{Na}$ altura em que decidiu compor a Vita de Rómulo, Plutarco tinha à disposição este acervo de informações, produto de um longo e intricado processo de transmissão, que combinava elementos do conto popular, mitologia e recriação literária, erudição histórica e especulação antiquària. Para seleccionar um tipo de material que remontava a um período muito distante e, conforme dissemos no início, entrava mais no plano mítico do que no domínio da história, Plutarco serve-se do logos para efectuar um processo de racionalização mitigado que se traduz, sobretudo, em dar preferência a versões com maior verosimilhança e mais atestadas pelas fontes. No entanto, o biógrafo nem sempre toma partido em relação às diferentes interpretações racionalizantes, optando por vezes por enumerar simplesmente as distintas abordagens; é o que acontece, por exemplo, com o episódio de Aca Larência 
(Rom. 4.3-4). Mostra-se ainda, como acontecia já com a Vita de Teseu, particularmente céptico em relação a certas variantes literárias, que vão contra a probabilidade histórica, conforme ilustra o juízo acintoso relatívamente ao poeta Símilo pela forma como tratou o episódio de Tarpeia \{Rom. 17.6-7), ou ainda a retracção perante a maneira como Butas explica o ritual dos Lupercalia \{Rom. $21.8)^{3}$. Já a grande renitência com que trata a hipótese de o corpo de Rómulo (Rom. 28) ascender aos céus juntamente com a alma parece entrar mais no domínio das convicções ético-filosóficas de Plutarco, uma vez que o biógrafo não se empenha propriamente em negar a apoteose do herói, mas antes a ideia de corpo e alma participarem em conjunto nesse processo, conforme argumenta, em termos que valerá a pena evocar (Rom. 28.10) ${ }^{4}$ :

Não é, portanto, necessário forçar a natureza para fazer subir aos céus o corpo das pessoas boas, mas pode-se crer com segurança que as suas virtudes e almas, de acordo com a natureza e com a justiça divina, ascendam da condição humana à de heróis, de heróis a semi-deuses e, finalmente, que de semi-deuses - como na iniciação mistérica, depois de se purificarem e santificarem, libertando-se de todos os elementos mortais e sensíveis - sejam elevadas a deuses; contudo, isso não acontece por decreto da cidade, mas segundo a verdade e a lógica aceitável, desta forma atingindo o fim mais belo e mais ditoso.

A este conjunto de factores que actuaram sobre a forma de trabalhar as fontes, convém juntar um outro, não menos importante e cuja influência se estende às restantes Vitae; referimo-nos às regras específicas do género biográfico, que implicam uma estética própria de selecção e arranjo do material disponível. Isso mesmo nos recorda Plutarco na abertura de algumas biografias, a fim de prevenir eventuais críticas dos leitores, preocupação idêntica à que demonstra relatívamente à explicação para a escolha do par Teseu-Rómulo, conforme se viu, e que toma os proémios deste tipo num espaço privilegiado para abordar algumas questões de carácter teórico e metodológico ${ }^{5}$. De facto, na abertura do prefácio às Vitae de Timoleonte e de

3 Ainda assim, a tendência para aceitar como verdadeiros os relatos que vão ao encontro de práticas rituais inscreve-se numa longa tradição historiográfica, que Plutarco também não deixa de seguir como critério valorativo, pese embora o risco de as explicações etiológicas poderem funcionar como argumentação circular: usam-se os cultos como forma de tomar plausíveis determinadas lendas e utilizam-se alguns relatos míticos (entendidos como repositório da memória colectiva e da identidade cultural) para explicar certos cerimoniais, ligando-os às raízes profundas do passado mais remoto.

Cf. também De E apud Delphos 390 d-f.

5 Neste ponto, retomámos alguns dos argumentos usados em LEÃo (2005a) 23-25. 
Emílio Paulo (1.1), Plutarco informa que começou por se dedicar à elaboração de biografias a pedido de amigos, entre os quais se contavam personalidades importantes, tanto gregas como romanas. Contudo, a essa motivação cedo ele juntou o gosto e proveito pessoais decorrentes do convívio com o exemplo das grandes figuras do passado. Portanto, será de admitir que a elaboração de uma espécie de 'espelho de virtudes' é que constitui o objectivo principal da sua escrita biográfica. No entanto, a concomitância, no passo agora referido, do termo historia levou muitos investigadores a procurar descobrir em Plutarco as marcas da indagação histórica, com resultados nem sempre elogiosos para o autor das Vidas Paralelas. Ora na abertura da biografia de Alexandre Magno, ele responde precisamente a esta crítica (Alex. 1.1-2):

Ao escrevermos neste livrinho a biografia do rei Alexandre e de César (que derrubou Pompeio), não faremos outros preâmbulos, dada a grande quantidade de acontecimentos envolvidos, para além de formular um pedido aos leitores: de, no caso de não relatarmos em pormenor todo e cada um dos eventos célebres, mas antes abreviarmos a maior parte, nos não julgarem mal. $\mathrm{Na}$ verdade, nós não escrevemos histórias mas sim biografias, nem sequer é nos acontecimentos mais espectaculares que reside especialmente a demonstração da virtude ou do vício; pelo contrário, muitas vezes um pequeno gesto, uma palavra ou uma brin- cadeira reflectem melhor o carácter do que os combates com baixas incontáveis ou fileiras cerradas ou os maiores cercos a cidades.

Este preâmbulo, justamente célebre, não só define de maneira mais precisa a índole das Vitae como esclarece melhor os seus objectivos, que já se adivinhavam no passo da Vita de Timoleonte. Plutarco não pretende ser um historiador, mas antes um biógrafo; por este motivo, pede aos leitores que lhe não censurem o facto de passar em branco acontecimentos que, pela sua importância, eram bem conhecidos e sobre os quais havia à disposição outros relatos de natureza histórica. Por conseguinte, Plutarco afirma-se um biógrafo, mas também não na forma plena em que hoje se entende o tenno; as Vitae não pretendem descrever toda a carreira de determinado homem ou mesmo definir o lugar que ocupa na história, embora possam acabar por fazê-lo, até porque as personalidades retratadas correspondem geralmente a grandes estadistas do passado. Os feitos destes heróis, qualquer que fosse a sua natureza, só lhe interessavam na medida em que permitissem esclarecer a verdade sobre o carácter que possuíam essas personalidades de excepção, acentuando assim o seu valor exemplar.

Ora no caso de heróis fundadores (como acontece com o tratamento dado a Teseu e a Rómulo), o percurso biográfico escolhido assume ainda mais claramente o carácter de arquétipo, na medida em que essas figuras representam, de forma metonimica, uma espécie de 
'genoma étnico' (como atrás dizíamos) da civilização a que deram origem. Ainda assim, também neste processo de modelação os parâmetros da escrita de Plutarco estavam já praticamente definidos pela tradição anterior. Para ilustrar este facto, aliás bem conhecido, bastaria evocar o aproveitamento ideológico de Teseu na tragédia ática ou o de Rómulo na literatura imperial. Em boa verdade, do ponto de vista histórico, tanto a existência de Rómulo como os feitos que lhe vêm atribuídos são mais do que duvidosos; no entanto, ainda que se postule a hipótese teórica de ter vivido efectivamente alguém com o mesmo nome no séc. VIII a.C., essa pessoa não foi, seguramente, o 'fundador' de Roma, pois o lugar já era habitado havia bastante tempo e, além disso, as próprias lendas pressupõem que a construção da urbe se traduziu num processo gradual e lento, de forma que cada um dos reis teria sido, à sua maneira, também o fundador de uma parte da cidade ${ }^{6}$. A ideia de um oikistes primordial que criasse o núcleo urbano a partir do nada afigura-se claramente influenciada pela historiografia grega e respectiva concepção do ritual de fundação (ktisis), acabando assim por gerar uma contradição dentro do cerne das lendas romanas.
Aliás, não é esta a única diferença clara e rica de consequências que encontramos entre o modelo helénico e romano. Os Gregos insistiam muito na noção de pureza originária, a ponto de os Atenienses, por exemplo, desenvolverem a crença de que os primeiros habitantes eram autochthones, isto é, haviam literalmente 'brotado do próprio solo' e, como tal, não tinham sido nunca estrangeiros ou colonos invasores ${ }^{7}$. Pode parecer um pormenor sem importância, mas a verdade é que, de forma consciente ou não, acabava por ter importantes consequências a nível legal, sobretudo no que se referia ao direito de propriedade (enktesis) sobre terras e outros bens imóveis. Um estrangeiro com autorização de residência oficializada e legal (como acontecia com um meteco) só obteria, mesmo assim, o direito à enktesis como sinal de reconhecimento e deferência especial e nunca em resultado das naturais expectativas de quem habitasse em território ático, ainda que o fizesse há muito tempo ${ }^{8}$. Se avançarmos para o domínio dos direitos de cidadania, será fácil reconhecer que Atenas estabeleceu as noções básicas daquele estatuto, traduzidas no princípio da soberania popular e na igualdade de todos os cidadãos: perante a lei (isonomia), no acesso ao poder (isocra-
6

As palavras de Tito Lívio são, a este nível, de uma clareza meridiana (2.1.2: omnes deinceps conditores partium certe urbis). Cf. ainda Cícero, Rep. 2.37; Políbio, 6.10.12-14.

1 Sobre esta questão, vide LEÃO (20056), esp. 53-68.

8 Se quiséssemos encontrar um paralelo discutível mas ainda assim ilustrativo do alcance simbólico da interdição, quase poderíamos dizer que alienar uma parcela da terra nutriz seria quase como 'vender a própria mãe'. 
cia) e na forma como gozavam da liberdade de expressão (isegoria). No entanto, da mesma forma que estabelecia a equivalência de todos os cidadãos perante a tutoria da lei, a democracia acentuava também os graus de exclusão, quer dentro do corpo cívico (no respeitante a mulheres e a menores) quer ainda e sobretudo fora dele (no tratamento dispensado a metecos, escravos e estrangeiros). No fundo, isto acaba por ser a expressão do próprio particularismo da pòlis, cujos ideais de autonomia obrigavam à contenção demográfica dentro de certos limites e constituíram, de resto, o principal entrave à união política dos Gregos, embora os não impedisse de reconhecerem a partilha da mesma identidade cultural.

O padrão romano comporta diferenças significativas, que se podem encontrar precisamente nas lendas fundacionais em geral e na Vida de Ròmulo em particular, ajudando a identificar o tal 'genoma étnico' antes mencionado. A ambiguidade relativa ao termo lupa tanto acentua o carácter extraordinário dos proto-romanos como denota a capacidade para singrar na vida a partir de inícios muito prosaicos; em todo o caso, a mera hipótese de ser 'filho de uma prostituta' implica um padrão civilizacional distinto da preocupação em insistir na pureza étnica, como faziam os Ateniense. A morte de Remo, suscitada por uma querela fútil, bem como as dúvidas que acompanharam a morte de Tito Tácio e do próprio Rómulo, poderiam apontar para a relativa facilidade com que o assassínio político era usado em Roma, onde não faltam exemplos desta prática extrema, em particular na parte final na República e durante o Principado; em todo o caso, é um expediente completamente distinto e muito menos humano que o mecanismo do ostracismo, desenvolvido pela experiência ática da democracia. $\mathrm{O}$ mesmo se pode afirmar relativamente à ideia de acolher marginais, ladrões e inimigos dentro do corpo de cidadãos, bem como quanto à generosidade na atribuição de asilo; desde a origem, Roma parece ter seguido o desígnio de integrar para poder crescer9. Aliás, Plutarco não deixou de registar este aspecto, ao comentar a forma como Rómulo lidou com o ataque de Ácron, rei de Cenina (Rom. 16.3):

Ora não só o dominou e abateu, como ainda pôs em fuga o exército, depois de entrar em combate, e conquistou também a cidade. Mesmo assim, não exerceu violência sobre os prisioneiros, mas ordenou-lhes que derrubassem as

Também aqui havia curiosas analogias no campo legal; ao longo da sua história, os Romanos revelaram-se particularmente generosos na concessão da cidadania e foi isso que lhes permitiu aumentar o corpo cívico para números impensáveis nas póleis gregas. No entanto e para nos mantermos dentro do paralelo com Atenas, enquanto a democracia era avara na concessão do direito de cidadania mas depois reconhecia igualdade perante a lei a todos os cidadãos, Roma seguia o processo contrário: concedia esse estatuto com relativa facilidade, criando porém um acentuado escalonamento no interior do corpo de cidadãos. 
suas casas e o seguissem até Roma, onde se tomariam cidadãos com direitos iguais. Em boa verdade, foi esta atitude, mais do que qualquer outra razão, que permitiu a Roma tomar-se grande: conciliar consigo mesma e integrar sempre os povos que ia vencendo.

Surpreendem-se, portanto, nas atitudes do fundador algumas das marcas do 'código étnico' que haveria de caracterizar os herdeiros do mesmo património civilizacional. No termo desta breve análise, porém, temos de reconhecer que resiste a mesma dúvida programática: as lendas fundacionais foram recolhendo, ao longo do seu processo de formação, o essencial da Romanitas ou serão antes, pelo contrário, uma Projecção no passado da forma como os Romanos se viam a si mesmos e gostavam de ser vistos pelos outros? A resposta para esta pergunta residirá, possivelmente, a meio caminho entre ambas as hipóteses formuladas. Em todo o caso, isso não altera — mas antes reforça - a dimensão paradigmática e simbólica da tradição reunida e tratada por Plutarco na Vida de Rómulo, a qual procurámos evocar ao longo deste estudo.

\section{BIBLIOGRAFIA}

\section{Edições, traduções e comentários}

ampolo, Carmine \& manfredini, Mario,

- Plutarco. Le Vite di Teseo e di Romulo,

Milano, Fondazione Lorenzo Valla, 21993.

Flacelière, R., Chambry, É. \& Juneaux, M., Plutarque. Vies I. Thésée - Rumulus,
Lycurgue - Numa, Paris, Coll. G. Budé, 1957.

Pérez Jiménez, Aurelio,

Plutarco. Vidas Paralelas. I. Teseo - Rómu-

lo, Licurgo - Numa, Madrid, Gredos, 1985.

Perrin, Bemadotte,

- Plutarch s Lives. Theseus and Romulus, Lycurgus and Numa, Solon and Publicola, Harvard, University Press, 1967.

\section{Estudos}

AMPOLO, Carmine,

"La paideia degli eroi fondatori L'educazione e la giovinezza nelle Vite di Teseo e di Romolo", in J. R. FERrEIRA (coord.), Plutarco educador da Europa, Porto, Fundação Eng. António de Almeida, 2002, pp. 281-292.

BRIQUEL, D.,

- "Perspectives comparatives sur la tradition relative à la disparition de Romulus", Latomus, 36 (1977) 253-282.

CORNELL, T. J.,

The beginnings of Rome, London, Routledge, 1995.

EDLUND, I. E. M.,

- "Must a king die? The death and disappearance of Romulus", PP, 39 (1984) 401-408.

ERBSE, FL,

- "Die Bedeutung der Synkrisis in den Parallelbiographien Plutarchs", Hermes, 84 (1956) 398-424.

FiALHO, Maria do Céu

- "Teseu em Plutarco à luz da tradição", in J. R. Ferreira (coord.), Plutarco educador da Europa, Porto, Fundação Eng. António de Almeida, 2002, pp. 67-79.

FLACELIÈRE, R.,

"Sur quelques passages des Vies de Plutarque. I. -Thésée - Romulus", REG, 61 (1948) 67-103.

HERTER, H.,

- “Theseus der Joner", RhM, 85 (1936) 
177-239.

LARMOUR, David, H. J.,

"Plutarch's compositional methods in the Theseus and Romulus", TAPhA, 118 (1988) 361-375.

LEÃO, Delfim F.,

"Alexandre Magno: da estratégia panhelénica ao cosmopolitismo", in A. CASANOva (coord.), Atti del convegno internazionale di studi "Plutarco e l'età ellenistica", Firenze, Università degli Studi di Firenze, 2005 $\alpha$, pp. 23-37.

- "Cidadania e exclusão: mecanismos de gradação identitària", in M. C. FIALHO, M. F. Sousa E Silva \& M. H. DA Rocha PEREIRA (coords.), $O$ desenvolvimento da ideia de Europa. Voi 1 De Homero ao firn da Època Clàssica, Coimbra, Imprensa da Universidade, 2005b, pp. 43-75.

Pelling, Christopher B. R.,

- "«Making myth look like history»: Plato in Plutarch's Theseus-Romulus", in A. PÉREZ JiMÉNEZ, J. GARCÍA LÓPEZ \& R. M. Aguilar (eds.), Plutarco, Platón y Aristóteles. Actas del $V$ Congreso Internacional de la I.P.S., Madrid, Ediciones Clásicas, 1999, pp. 431-443.

PÉREZ JIMÉNEZ, Aurelio,

- "Actitudes del hombre frente a la Tyche en las Vidas Paralelas de Plutarco", BIEH, 7 (1973) 101-110.

RODRIGUES, Nuno Simões,

Mitos e lendas - Roma antiga, Lisboa, LivroseLivros, 2005.

TITCHENER, F. B.,

- "Critical trends in Plutarch's Roman Lives, 1975-1990”, ANRW 11.33.6 (1992), pp. 4128-4153, esp. 4131.

WALKER, H.,

Theseus and Athens, Oxford, University Press, 1995. 